\title{
Objective and subjective measures of distractibility
}

\author{
S. V. AUSTIN and D. R. HEMSLEY \\ Institute of Psychiatry, De Crespigny Park, Denmark Hill, London SE5 8AF, England
}

\begin{abstract}
The present study reports relationships between objective and subjective measures of distractibility. Four tasks were performed by a group of normal subjects under two conditions, no distraction and distraction. Within the group, there was little relationship between measures of distractibility. In contrast, speed measures derived from three of the tasks were highly positively correlated. Distractibility scores were not related to self-reports of ability to concentrate and susceptibility to distraction. The subjective measures did, however, correlate significantly with the speed scores.
\end{abstract}

There have been numerous studies of "distractibility" or "defective attention" in schizophrenia (e.g., Hemsley \& Zawada, 1976; McGhie, Chapman, \& Lawson, 1965). Relative to normals, schizophrenics appear less able to exclude irrelevant stimulation when performing a task. The use of the term "attention" has, however, varied considerably, as several authors have indicated (e.g., Kay \& Singh, 1974). Even if only the selective aspects of attention are considered, there are conflicting findings on the relationships between purported measures of this ability. Such relationships are of importance if defective attention is to be considered the major cognitive deficit in schizophrenia and possibly causal in relation to other aspects of symptomatology.

Kopfstein and Neale (1972) found little common variance shared by supposed measures of attention within a mixed group of schizophrenic and nonschizophrenic subjects; the tasks included reaction time, measures of overinclusion, vigilance, and size estimation. The authors concluded, "While each of the tasks may bear some relationship to some aspect of attention, the relationship among them is surprisingly weak." They indicate that the attention construct requires more precise definition. In contrast, Golden, Marsella, and Golden (1975) claim that resistance to interference, as measured by the Stroop Color and Word test (Stroop, 1935), is a potentially viable diagnostic dimension. In their study, 219 subjects were tested on a battery of 20 cognitive tasks; 12 of these were considered to involve a subject's ability to effectively select or screen material in order to avoid distraction and maintain optimal performance. Subjects were classified as high or low resistant to interference on the basis of their performance on the Stroop test. The groups differed on most of the tasks related to screening ability but on none of the tests unrelated to screening. However, the

Thanks are due Mr. B. S. Everitt for statistical advice. S. V. Austin is now at Preswylfa Child and Family Center, Cardiff, Wales. tasks employed were not carried out under conditions of no distraction and distraction, and possessed only face validity as measures of selective attention. Moreover, the precise nature of what is being measured by the Stroop test has still to be clarified (Majeres, 1974).

The main aim of the present study was to investigate the relationships between four measures of distractibility. The selected tasks had in common the requirement that subjects perform under two conditions, no distraction and distraction. Irrelevant items of the same nature and in the same modality as those relevant to successful task performance were present in the distraction condition. Three of the tasks also yielded speed measures. The second aim was to relate objective measures of distractibility to self-reports of ability to concentrate and susceptibility to distraction. A close correspondence between such measures has often been assumed in reports of subjective cognitive disturbance in schizophrenics (McGhie \& Chapman, 1961).

\section{METHOD}

\section{Subjects}

The subjects were 80 normals, consisting of 20 monozygotic twin pairs and 20 dizygotic twin pairs, since the present report formed part of a larger investigation concerning the heritability of measures of distractibility and speed; those findings will be reported in a subsequent article. It was also possible for the co-twin to provide a rating of his twin's distractibility and ability to concentrate. The mean age of the subjects was 20.3 years and the mean IQ derived from the Mill Hill synonym score was 112.6.

\section{Tasks}

Auditory distraction task. This task was based on that described by McGhie et al. (1965) in their study of schizophrenic distractibility. It requires subjects to repeat lists of digits presented auditorily in a female voice. In the distraction condition lists are interspersed with digits spoken in a male voice. There were 4 practice trials and 20 test trials, with half of the latter randomly allocated as "distraction" trials.

Visual distraction task. This choice reaction time card-sorting task formed part of that employed by Hemsley (1976) in a study of attention and information processing in schizophrenia. It requires that cards be sorted into piles according to a figure on 
each card. In the no-distraction condition there is a single figure on each card. In the distraction condition there is an additional irrelevant figure in the corner of each card; sorting is based on the symbol in the center. The conditions employed were a single level of stimulus uncertainty (3 "bits") and three levels of response uncertainty, subjects being required to sort into two, four, or eight piles. Thus, each subject sorted under six conditions that were presented in a separately randomized order for each pair of twins.

Associative distraction task. This was a modified version of that devised by Chapman (1958) to investigate the effect of associative distraction on schizophrenic performance. Thirty word sets, each consisting of one sorting word plus three guide words, were selected from Chapman's material and formed the distraction items. From these, a second list of 30 no-distraction sets was constructed by altering the sorting word on each set to another member of the same conceptual category, so that, although the correct answer remained the same, there was no longer an associate among the guide words. Subjects were required to choose the word that could be "called by the same name" as the sorting word.

Visual reaction time task. This task was devised by Thompson (1973). Simple reaction time to a visual stimulus was assessed under two conditions, no distraction and distraction. In the latter condition, one or two additional lights came on slightly after the response stimulus but before the subject had completed his reaction. There were 110 no-distraction and 84 distraction trials.

Concentration questionnaire. The twins were required to answer four questions, each on a 5-point scale: (1) How good are you at concentrating? (2) How good is your twin at concentrating? (3) How easy are you to distract? (4) How easy is your twin to distract? All questions were scored so that good concentration and low distractibility gave a high score; they were therefore expected to correlate negatively with the objective measures of distractibility.

The raw scores for the four tasks were speed and error measures for the no-distraction (ND) and distraction (D) conditions. From each pair of raw scores a distractibility score was calculated as $d / N D \times 100$ (where $d=D-N D$ ). Speed scores were available from Tasks 2,3 , and 4 , error scores from 1 and 3 . From these were derived seven distractibility measures: on Tasks $1-4$, respectively, the effect of distraction on total errors (1), the effects of distraction on time taken at each of three levels of response uncertainty $(2,3,4)$, the effects of distraction on both time taken (5) and errors (6), the effect of distraction on mean reaction time (7).

\section{RESULTS}

Multivariate analyses of variance were carried out on each task separately (Finn, 1974) to assess the effects of distraction, since each task yielded more than one score. A summary of subsequent univariate analyses on the variables of interest is presented in Table 1 . There were clear effects of distraciion on all measures.

\section{Relationships Between Objective Measures}

Product-moment correlations between distractibility measures were calculated. Within a task measures tended to correlate significantly; however, between tasks only one correlation was significant, that between the effect of distraction on errors on the auditory distraction task and the effect on mean reaction time on Task $4(\mathrm{r}=.28$, $\mathrm{p}<.05$ ).
Table 1

Effects of Distraction on Task Performance

\begin{tabular}{|c|c|c|c|c|c|c|}
\hline \multirow[b]{2}{*}{ Task } & \multirow{2}{*}{$\begin{array}{l}\text { Vari- } \\
\text { able }\end{array}$} & \multicolumn{2}{|c|}{ ND } & \multicolumn{2}{|c|}{ D } & \multirow[b]{2}{*}{$\mathrm{F}$} \\
\hline & & Mean & SD & Mean & SD & \\
\hline 1 & 1 & 2.9 & 3.4 & 7.5 & 7.1 & $72.6^{*}$ \\
\hline 2 & $\begin{array}{l}2 \\
3 \\
4\end{array}$ & $\begin{array}{l}15.6 \\
23.2 \\
27.6\end{array}$ & $\begin{array}{l}3.0 \\
3.8 \\
4.3\end{array}$ & $\begin{array}{l}17.3 \\
25.0 \\
34.4\end{array}$ & $\begin{array}{l}3.7 \\
5.8 \\
8.5\end{array}$ & $164.1 \dagger$ \\
\hline 3 & $\begin{array}{l}5 \\
6\end{array}$ & $\begin{array}{r}109.2 \\
.7\end{array}$ & $\begin{array}{r}28.9 \\
1.1\end{array}$ & $\begin{array}{r}137.1 \\
3.2\end{array}$ & $\begin{array}{r}32.7 \\
2.5\end{array}$ & $\begin{array}{l}219.1^{*} \\
157.6^{*}\end{array}$ \\
\hline 4 & 7 & 347.7 & 49.0 & 397.6 & 45.1 & $287.0 *$ \\
\hline
\end{tabular}

Note $-d f=1,40 ; p<.0001$.

*Univariate $F$ ratio. $\quad$ Multivariate $F$ ratio.

In contrast, the correlations between the 10 raw speed scores ( 5 with no distraction, 5 with distraction) were all highly significant, both within and across tasks. All but one were significant at the $1 \%$ level (range .33 to $.90)$; the other was significant at the $5 \%$ level.

\section{Relationships Between Subjective Measures}

As a check on the reliability of subjective reports, the correlations between ability to concentrate and susceptibility to distraction were calculated, both for self-report and twin report data; these were, respectively, $.52(\mathrm{p}<.005)$ and $.28(\mathrm{p}<.05)$. Also calculated was the agreement between self and twin reports of ability to concentrate $(r=.42, p<.01)$ and self and twin reports of susceptibility to distraction $(r=.35, \mathrm{p}<.01)$. These findings suggest that the subjective reports assess a meaningful dimension of behavior.

\section{Relationships Between Objective Measures and Self-Report Data}

Objective measures of distractibility. Of the correlations between self-reported concentration and distractibility and objective measures of distractibility, only two were significant, that between self-reported concentration and the increase in errors on the associative distraction task $(r=-.29, \mathrm{p}<.01)$ and that with the slowing produced on one of the conditions of the card-sorting task (Variable 3) by distraction $(r=-.26$, $\mathrm{p}<.05$ ).

Raw speed scores. In contrast to the preceding findings, all speed measures correlated negatively and significantly with self-report of ability to concentrate (range -.24 to -.44 ). That is, the faster the task performance, the greater was the self-reported ability to concentrate. The majority of speed measures ( 7 out of 10) also correlated negatively and significantly with selfreports of susceptibility to distraction.

\section{DISCUSSION}

The present findings are consistent with those obtained by Kopfstein and Neale (1972). The results of Golden et al. 
(1975) are, however, conflicting; it may be that their two kinds of tasks differed on a factor other than the presence or absence of interfering stimuli. In their study, the same tasks were not performed under two conditions, distraction and no distraction, as in the present investigation. Thus, even if one restricts the term "distractibility" to the difference in performance on two tasks, one having distracting stimuli present in the same modality, there is little relationship between such measures among normals; significant correlations might emerge with a more heterogeneous sample including psychiatrically disturbed subjects. It may be necessary to distinguish the tasks in which there is a clear physical cue separating relevant and irrelevant stimuli (e.g., Task 1) from those in which the distraction is on the basis of associative strength (e.g., Task 3 ). The differing mechanisms of selectivity of information processing have been considered by Treisman (1969). The attentional disturbance in schizophrenia must therefore be specified both in terms of mechanism and modality. In view of these findings, it is perhaps not surprising that there was little relationship between subjective estimates of distractibility and ability to concentrate and the objective measures.

In contrast, the correlations between the speed measures were all highly significant, despite being derived from diverse tasks; this is consistent with Birren, Riegel, and Morrison (1962). It has been argued that such correlations are even higher in abnormal groups (Nelson, 1953; Yates, 1973). It is of particular interest since recent work has suggested that slowness rather than distractibility may be important in relation to cognitive deficits in schizophrenia (e.g., Hemsley, 1976). In addition, the speed measures were significantly related to the subjective reports. Some of the subjective reports of cognitive disturbance in schizophrenia (Chapman, 1966; Freedman \& Chapman, 1973) may therefore reflect slowness rather than a disturbance of selective attention, as originally indicated by McGhie and Chapman (1961). However, the failure to find significant correlations with distractibility measures could be attributable to the lower reliability of difference scores in comparison with the raw speed measures.

\section{REFERENCES}

Birren, J. E., Riegel, K. F., \& Morrison, D. F. Age differences in response speed as a function of controlled variations of stimulus conditions: Evidence of a general speed factor. Gerontologia, 1962, 6, 1-18.

ChAPMAN, J. The early symptoms of schizophrenia. British Journal of Psychiatry, 1966, 112, 225-251.
Chapman, L. J. Intrusion of associative responses into schizophrenic conceptual performance. Journal of Abnormal and Social Psychology, 1958, 56, 374-379.

Finn, T. D. A general model for multivariate analysis. New York: Holt, Rinehart, \& Winston, 1974.

Freedman, B., \& Chapman, L. J. Early subjective experience in schizophrenic episodes. Journal of Abnormal Psychology, $1973,82,46-54$.

Golden, C. J., Marsella, A. J., \& Golden, E. E. Cognitive relationships of resistance to interference. Journal of Consulting and Clinical Psychology, 1975, 43, 432.

Hemsley, D. R. Attention and information processing in schizophrenia. British Journal of Social and Clinical Psychology, 1976, 15, 199-209.

Hemsley, D. R., \& Zawada, S. L. "Filtering" and the cognitive deficit in schizophrenia. British Journal of Psychiatry, 1976, 128, 456-461.

KAY, S. R., \& Singh, M. M. A temporal measure of attention in schizophrenia and its clinical significance. British Journal of Psychiatry, 1974, 125, 146-151.

Kopfstein, J. H., \& Neale, J. M. A multivariate study of attention dysfunction in schizophrenia. Journal of Abnormal Psychology, 1972, 80, 294-298.

Majeres, R. L. The combined effects of stimulus and response conditions on the delay in identifying the print color of words. Journal of Experimental Psychology, 1974, 102, 868-874.

McGhie, A., \& Chapman, J. Disorders of attention and perception in early schizophrenia. British Journal of Medical Psychology, 1961, 34, 103-116.

McGhie, A., Chapman, J., \& Lawson, J. S. The effect of distraction on schizophrenic performance: 1. Perception and immediate memory. British Journal of Psychiatry, 1965, 111, 383-390.

Nelson, E. H. An experimental investigation of intellectual speed and power in mental disorders. Unpublished $\mathrm{PhD}$ thesis, University of London, 1953.

STroop, J. R. Studies of interference in serial verbal reactions. Journal of Experimental Psychology, 1935, 18, 643-662.

Tномpson, A. A. Reaction time, signal processing, and personality. Unpublished $\mathrm{PhD}$ thesis, University of London, 1973.

Treisman, A. M. Strategies and models of selective attention. Psychological Review, 1969, 76, 282-299.

YATES, A. J. Abnormalities of psychomotor functions. In H. J. Eysenck (Ed.), Handbook of abnormal psychology. New York: Pitman Medical, 1973. Pp. 261-283.

(Received for publication May 22, 1978.) 